\title{
MENJEMBATANI KRISIS ADVOKASI TERHADAP TKW INDONESIA DILUAR NEGERI
}

\author{
Hasanatul Jannah \\ Kementerian Agama Kabupaten Pamekasan \\ Email: Hasanatul Jannah@yahoo.co.id
}

\begin{abstract}
Abstrak
Sebagai salah satu penghasil devisa negara dan mendapat julukan yang begitu tehormat dari negara sebagai Pahlawan Devisa, TKW Indonesia seharusnya mendapat perhatian tersendiri dari pemerintah maupun pihak yang terkait, sehingga terkirimnya para TKW keluar negeri memiliki jaminan keselamatan. Untuk itu diperlukan adanya kesepakatan antara pihak pengirim dengan penerima TKW agar kehadiran TKW bisa memperoleh perlindungan di Negara tempat mereka bekerja. Seharusnya berbagai kasus yang banyak menimpa para TKW selama ini seperti penganiaaan, pelecehan seksual dan tindak kekerasan lainnya baik yang di ketahui publik maupun tidak, menjadi pelajaran penting bagi bangsa Indonesia.

As one of state foreign exchange producer and the hero of foreign exchange, Indonesian migrant workers should get sufficient attention from the government and all parts which are related to their process of being migrant workers in order they get safety guarantee in the countries they work. Therefore, it is a need to have an agreement between internal agent (that sends the workers) and external agent (that accept and manage the workers) to make sure that the migrant workers will get protection. What have been experienced, so far, by migrant workers such as mistreatment, sexual harassment and violence which are publicly known or ice versa should be an important lesson for Indonesia.
\end{abstract}

Kata Kunci: TKW, penganiayaan, pelecehan, advokasi

Bekerja merupakan sebuah keniscayaan dan ikon utama pembentukan eksistensi manusia dalam kehidupan. Agama Islam menempatkan nilai suatu pekerjaan sebagi sebuah ibadah, senagaiman al-Qur'an dengan tegas menjelaskan bahwa seorang manusia tidak akan memperoleh sesuatu selain apa yang dia kerjakan (QS. 53:39).

Seorang yang bekerja akan bermental murni, dan yang tidak bekerja akan kehilangan kontaknya dengan realitas sehingga kemampuan mentalnya akan kurang bermanfaat. ${ }^{1}$ Pekerjaan memainkan peranan yang sangat penting dalam proses realisasi diri manusia sebagai makhluk yang memiliki

${ }^{1}$ Bani Sadr, Buruh, kerja E Islam, (Yogyakarta: shalahuddin Press, 1985). 22. diri. Menurut Franz Von Magnis proses realisasi diri dalam sebuah pekerjaan sebagai sebuah bentuk bukti bahwa bekerja adalah menyalurkan bakat dan cita-cita untuk menjadi manusia nyata. ${ }^{2}$

Memiliki pekerjaan merupakan suatu keharusan yang terus diupayakan walaupun harus melintasi negara lain. Salah satu pekerjaan yang paling beresiko namun paling menjanjikan dari segi penghasilan adalah menjadi tenaga kerja wanita (TKW) ke luar negeri. Tentu saja konsekwensi menjadi TKW keluar negeri adalah meninggalkan keluarga, suami, dan anak, namun konsekwensi yang

${ }^{2}$ Franz Von Magnis, Soerjanto pospowardojo \& Bertens (red), Sekitar Manusia: bunga rampai tentang filsafat manusia, (Jakarta: gramedia, 1983), 79. 
paling mengancam adalah keselamatan jiwa para TKW, terutama yang menyangkut berbagai kasus yang belakangan semakin marak menimpa para TKW Indonesia diluar negeri.

Sebenarnya persoalan TKW bukan persoalan baru lagi, karena pada tahun-tahun sebelumnya bahkan sudah sejak lama banyak kasus-kasus penganiayaan, pemerkosaan bahkan pembunuhan menimpa para TKW Indonesia. Bahkan yang lebih tragis lagi dilansir dari berbagai pemberitaan, bahwa telah banyak ditemukan sejumlah TKW Indonesia dijual untuk dijadikan objek seks, jual beli tersebut dilakukan secara terpaksa dengan harga beli tertentu untuk sekali pelayanan.

Berbagai berita dan cerita seputar TKW sering muncul di permukaan, baik melalui media cetak, televisi, maupun cerita dari mulut ke mulut. Ada yang bernasib baik, tapi tidak sedikit yang bernasib memilukan, mengenaskan dan penuh peenderitaan. Semua penganiayaan yang diterima para TKW adalah kekerasan dalam bentuk fisik bahkan mental. Pastinya, berita dan cerita mengenaskan tentang TKW selalu ada dan tidak pernah surut.

Pada akhirnya persaingan dan kompentensi pengetahuan serta keterampilan sebagai TKW (dalam hal ini PRT) menjadi ketat dan kompleks. Kompleksitas ini memunculkan permasalahan - permasalahan, sadar atau tidak sadar, tepaksa atau dipaksa menyeret serta menjerumuskan para TKW bersikap lebih simple lagi dalam mengatasi dan survive menghadapi hidup. Jual jasa sebagai PRT dikalahkan oleh TKW dari negara lain, maka "Jual apa saja termasukjual fisik dengan begitu saja bisa terjadi“. Ketidakmampuan pemahaman yang disebabkan rendahnya pendidikan dan keterampilan menjadikan TKW dari Indonesia tidak memiliki nilai tawar (bargaining position) yang kuat, sehingga seiring mencuatnya berbagai kasus yang melibatkan TKW Indonesia baik sebagai subjek ataupun objek selalu memunculkan kontroversi - konroversi.
Sebagai bangsa yang mengedepankan penegakan prinsip-prinsip kemanusiaan dan jelas dituangkan dalam Undang - undang Dasar 45 dan mempunyai kerangka hukum yang kuat, jelas sekali kasus - kasus dan berita yang diilustrasikan tersebut sangat memilukan sekaligus memalukan bangsa Indonesia. Penjualan TKW tersebut sama halnya menjual bangsa Indonesia, untuk itu perlu dicarikan solusi yang memadai, salah satunya dengan memberikan advokasi yang signifikan.

\section{Menjadi TKW Demi Kesejahteraan Keluarga}

Pada dasarnya menjadi TKW bagi sebagian masyarakat Indonesia merupakan suatu pilihan yang harus dipilih, sebagai sebuah implikasi dari mendesaknya berbagai kebutuhan. Akibat dari desakan tersebut menjadi TKW bagi mereka merupakan pilihan cepat untuk segera menyelesaikan himpitan ekonomi keluarga, walaupun pilihan tersebut terkesan pada sebuah pilihan pragmatis.

Pola pragmatisme muncul ketika masyarakat memaksa mencari peluang untuk mempertahankan dan mengembangkan keadaan sosial ekonominya. Konsep pragmatisme yang muncul dari para TKW menekankan hubungan yang erat antara pengetahuan dan tindakan mengatasi masalah (problem-solving action). Demikian halnya jika diikuti dengan kondisi riil masyarakat yang masih rendah pengetahuan dan skill, serta berkurangnya lapangan kerja ditambah tidak adanya keseimbangan antara kebutuhan yang harus dipenuhi dengan apa yang diperoleh. Menurut Bani Sadr ada tiga macam bentuk kerja: pertama, bentuk kerja manual, kedua, bentuk kerja administrative dan ketiga, bentuk kerja innovative. ${ }^{3}$ TKW dalam hal ini masuk kategori bentuk kerja manual.

Bagi para TKW, pilihan untuk menjadi TKW merupakan sebuah impian untuk mewujudkan kemapanan perekonomian

${ }^{3}$ Bani Sadr, Buruh, kerja E Islam, 21. 
keluarga sekaligus merupakan keterpaksaan dalam sebuah pekerjaan. ${ }^{4}$ Tentu saja impian tersebut tanpa mempertimbangkan ekses-ekses negatif yang akan mereka terima, dimana posisinya sangat rentan terhadap segala macam bentuk kekerasan dan eksploitasi.

Bagaimanapun juga TKW adalah seorang individu dan seorang perempuan yang memiliki kemampuan terbatas karena rendahnya tingkat pendidikan, keterampilan serta lingkungan dan konteks budaya yang kurang mendukung. Kondisi tersebut memunculkan sebuah sikap pragmatis, praktis sekaligus konsumtif. Dalam bahasa yang lebih sederhana adalah bagaimana secepat mungkin mendapat materi berupa uang atau bayaran yang lebih dengan hanya melakukan pekerjaan yang sederhana tanpa latar belakang kompetensi pendidikan dan ketrampilan (Skill) yang memadai. Maka pilihan Pragmatis adalah menjadi TKW, yang sebagian besar ditempatkan sebagai PRT dinegara-negara maju yang memiliki pendapatan perkapita tinggi. Negara-Negara Teluk serta Negara Asia seperti Malaysia, Taiwan merupakan muara tujuan faforit para TKW Indonesia. Ruang kosong dalam strata social Negara - Negara maju ada pada level jasa Pembantu Rumah Tangga ( PRT ), dalam domain ekonomi adalah lapangan pekerjaan dalam level paling bawah. Akan tetapi menjadi lahan yang sangat menggiurkan bagi TKW Indonesia karena nominal atau gajinya dalam setiap bulan berada diatas rata-rata perkapita di negerinya sendiri.

Sikap Praktis dari para TKW dapat ditunjukan pada betapa rendahnya TKW memahami dan mengerti akan hak dan kewajiban yang didasarkan pada ketentuan hukum, sehingga ketika muncul persoalan-

${ }^{4}$ Keterpaksaan mempunyai dua sisi, pertama, apa yang dikerjakan tidak dapat dipilih sendiri, artinya pekerja bersedia uuntuk mengerjakan apa saja dan tidak dapat memilih karena yang dikerjakan adalah apa yang dikehendaki oleh majikannya, pekerjaan ini sebagai dasar untuk memuaskan pemenuhan kebutuhan hidup fisik. Kedua, pekerjaan upahan yang mengasingkan kebebasan manusia karena orang lain yang menentukan jenis pekerjaan, pekerja justru ditundukkan oleh orang lain.( Franz Von Magnis, Sekitar...., 87-88. persoalan yang menimpa para TKW terutama menyangkut masalah hukum, para TKW tidak memiliki sandaran untuk melindungi hak dan kewajibanya. Kesimpulannya, satu-satunya alasan menjadi TKW adalah "memperbaiki taraf kehidupan" atau mencari penghasilan yang lebih tinggi untuk mendapatkan legalitas status social yang berdasar pada ideology materialism sebagai latar belakang sikap konsumerisme.

\section{Konsekwensi Menjadi TKW}

Keberadaan TKW diprediksi berbagai kalangan sebagai awal dari sebuah korban kebijakan akibat penggelindingan arus globalisasi ekonomi. Akhirnya pro dan kontra bermunculan merespon pengiriman TKW keluar negeri. Pengiriman TKW tersebut mendapat sorotan dari berbagai LSM di Indonesia. Ada yang menghimbau kepada pemerintah untuk menghentikan pengiriman TKW, menghentikan sementara bahkan menghimbau tetap mengirim TKW dengan kebijakan yang tidak merugikan TKW baik secara Materi, Fisik, psikis. Himbauan tersebut di sinyalir akibat kedutaan besar seperti Di arab Saudi, Malaysia dan Negaranegara kantong TKW Indonesia lainnya kesulitan bahkan seringkali tidak bisa ikut campur dalam urusan Peradilan .

Satu sisi desakan pemberhentian Pengiriman TKW akan bertentangan dengan APJATI dan para pencari kerja (TKW) karena menyangkut Kompleksitas berbagai kepentingan, sisi yang lain pengiriman tersebut melahirkan Ekses-Ekses yang lebih membahayakan pada dimensi kualitas masyrakat itu sendiri. Dapat di lihat secara verbal bahwa rata-rata para TKW yang di kirim hanya memiliki basic Pendidikan yang rendah, sehingga hanya Menempati posisi pekerjaan yang Rentan terhadap berbagai resiko.

Persoalan-persoalan yang dihadapi TKW sangat beragam, mulai tidak berdokumen sejak dari pemberangkatan sampai pemulangan ke Indonesia, tuntutan ekonomi kelu- 
arga, jeratan hutang, penganiayaan, penipuan, pemerasan dan pelanggaran HAM dan terjeratnya ikatan dengan jaringan calo/ tekong. ${ }^{5} \quad$ Kompleksitas problem-problem yang mendera para TKW tersebut menjadi bagian yang tidak terpisahkan dari kehidupan para TKW, bahkan cenderung dianggap sebagai konsekwensi logis yang harus diterima para TKW.

Kasus demikasus terjadi padaTKWkarena pelebaran sejumlah akses dan melonggarkan sejumlah regulasi terkait dengan proses pemberangkatan TKW ke luar negeri tidak dibarengi dengan perangkat hukum yang memadai dalam rangka menjamin hak-hak normatif TKW. Salah satu fakta konkretnya adalah karena hampir tidak ditemukan pembekalan terhadap TKW terkait dengan pemahaman hak-hak normatif tenaga kerja sebelum berlabuh menuju negeri impiannya.

Konsekuensinya, beragam bentuk penganiayaan yang tidakjarang melahirkan depresi dan rasa traumatik yang cukup mendalam bagi para TKW menjadi tidak terhindarkan. Harga diri menjadi hilang karena negeri sendiri pun kadang lalai dalam memberikan perlindungan yang memadai.

Kekerasan dan Penyiksaan yang dialami para TKW merupakan salah satu pelanggaran HAM yang cukup berat.Oleh karenanya harus dibawa ke pengadilan mahkamah internasional. Pemerintah, harus mengambil langkah-langkah yang jelas, tegas dan strategis terhadap kasus kekerasan yang dialami TKW yang berada di luar negeri.

\section{Reformulasi Kebijakan Hukum yang Ber- basis Kemaslahatan}

Sebagai salah satu penghasil Devisa Negara dan mendapat julukan yang begitu terhormat dari Negara sebagai Pahlawan Devisa, TKW Indonesia sudah selayaknya mendapat perhatian tersendiri bagi pemerintah. Baik pemerintah maupun pihak

${ }^{5}$ Padriono, sugiyanto, heru santoso dan hesti $\mathrm{R}$. wijaya, Liku-liku perjalanan TKI/TKIW berdokumen ke Malaysia, ( Malang: Gema Press, 1999), hal. 3. yang terkait sehingga terkirimnya para TKW keluar negeri memiliki jaminan keselamatan. Untuk itu diperlukan adanya kesepakatan antara pihak pengirim dengan penerima TKW sehingga kehadiran TKW bisa memperoleh perlindungan .selama ini berbagai Kasus yang banyak menimpa para TKW seperti Penganiaaan,Pelecehan seksual dan tindak kekerasan lainnya baik yang di ketahui Publik maupun tidak, seharusnya menjadi pelajaran Penting bagi bangsa Indonesia.

Pada dasarnya, pemerintah telah melakukan sejumlah kebijakan sebagai upaya perlindungan terhadap TKW, seperti mengeluarkan berbagai memorandum of understanding (MoU) dengan pemerintah Malaysia. Walaupun sebagian elemen menyayangkan bahwa MoU itu tidak mengarah pada perlindungan terhadap hak-hak normatif TKI/TKW. Sehingga seringkali penganiayaan tetap terjadi.

Untuk itu perlu difikirkan kembalai tentang urgensi sinergi yang lebih kuat antara PJTKI, pemerintah, dan TKI. Penekanan pada koordinasi yang lebih kuat akan memperkecil agen-agen TKI illegal. upaya ini membutuhkan sosialisasi yang terusmenerus untuk meminimalisir pengiriman TKW illegal dan tidak berkwalitas. Sehingga nasib para TKW Indonesia lebih jelas dan terjamin. Demikian pula Para calon TKW perlu diberi penekanan agar berhati-hati dalam memilih PJTKI, sehingga terhindar dari berbagai kasus dan pemulangan TKW ilegal.

Pemerintah diharapkan memiliki kebijakan yang tegas dalam menyikapi kasus-kasus yang menimpa para TKW Indonesia seperti penggodokan SDM para TKW sebelum di berangkatkan, pendataan yang akurat terhadap PJTKI, karena semakin Maraknya pengiriman TKI illegal dan membantu memberikan Pertimbangan Rasional jika memang TKW masih tetap di berangkatkan. Yang tidak kalah pentingnya pemerintah Indonesia di harapkan mampu memiliki 
bergaining position kuat dengan negara yang menjadi tujuan pengiriman TKW, sehingga para TKW di negeri orang merasa nyaman aman dan terlindungi dalam bekerja

Artinya system perekrutan TKW diperketat dan selektif, yang dikirim harus berkwalitas, siap mental untuk bekerja dengan kultur yang berbeda karena TKW bukan komoditas dagang.

Mengingat kondisi riil TKW yang masih dipandang rendah pengetahuan, pengalaman dan keterampilannya, maka perlu intervensi dan stimulasi dari pemerintah, hal tersebut sangat penting dan dipandang sebagai langkah strategis dalam proses pemberdayaan, peningkatan taraf kehidupan dan keamanan.

Dibutuhkan keseriusan dalam menangani persoalan-persoalan yang dihadapi para TKW, baik yang bersifat psikis-kultural maupun persoalan hokum sehingga diperlukan peningkatan pelayanan crisis center dan bantuan hokum yang lebih bersifat realistis.

Madelina K. Hendytio menawarkan jenisjenis kebijakan yang perlu diperjuangkan pemerintah menyangkut pemberdayaan pekerja, antara lain: (a) Upaya perbaikan melalui perubahan institusi-institusi yang telah meletakkan pekerja pada sisi subordinasi; (b) Memberikan jaminan perlakuan secara adil terhadap pekerja; (c) Memberikan tingkat kesejahteraan yang memadai; (d) Meningkatkan kemampuan fisik dan keterampilan sesuai dengan jenis pekerjaan; (f) Pemenuhan hak-hak pekerja lainnya. ${ }^{6}$

Pemerintah dan semua pihak yang terkait dalam proses pengiriman TKW harus mampu membuat kebijakan yang relative aman, sebagimana didiskripsikan Anthony Giddens tentang strategi dalam investasi social', karena hal tersebut manyangkut kehidupan manusia bekerja, maka perlunya dorongan kebijakan tempat kerja yang ramah keluarga

${ }^{6}$ Madelina K. Hendytio Onny S. Prijono \& AMW Pranarka (penyunting), Pemberdayaan, konsep, kebijakan \& Implementasi, (Jakarta: CSIS, 1996), 178.

${ }^{7}$ Anthony Giddens, The Third Way: jalan ketiga pembaharuan demokrasi social, (Jakarta: Gramedia, 1999), hal. 146. (friendly workplace policies) sesuatu yang juga bisa dicapai melalui kerjasama antara sektor publik dan sektor swasta, sehingga dapat membantu mendamaikan berbagai kepentingan yang saling bertabrakan, juga mampu menciptakan keamanan perjalanan ke dan dari tempat kerja.

Pengurangan pengiriman TKW ke luar negeri sudah semestinya bukan hanya dalam wacana pemikiran saja, namun perlu direalisasikan dalam peranan penting pemerintah dalam menginvestasikan sumber daya manusia (SDM) dan infrastruktur yang diperlukan untuk mengembangkan budaya kewirausahaan.

Salah satu Wacana menarik adalah dengan melakukan moratorium (penghentian sementara) pengiriman TKW ke luar negeri serta perlunya pengajuan kasus ke Mahkamah Internasional. Hal ini perlu ditindaklanjuti sehingga bukan hanya merupakan wacana belaka. Konsekuensi ini layak diperhatikan SelamaIndonesiabelum mampumemberikan kontribusi berarti dalam penambahan lapangan pekerjaan yang signifikan dan luas kepada warganya di negeri sendiri.

Pemerintah harus mampu melakukan negosiasi mendalam dengan Negara tujuan TKW bekerja, hal tersebut sangat penting untuk kelangsungan hidup TKW Indonesia di luar negeri.

Tim pengawas TKW di luar negeri menjadi perlu dibentuk, untuk mempermudah dan mengakses lebih cepat bila ada TKW yang dianiaya atau menderita saat bekerja.Karena sudah menjadi tanggung jawab bersama dimana TKW harus diberdayakan, dilindungi dan diawasi agar tidak terjadi penganiayaan.

\section{Kesimpulan}

Terlantarnya nasib para TKW yang tersandung berbagai kasus menjadi indikasi masih lemahnya kebijakan pemerintah dan menjadi pengingkaran atas hak warga.Jelas, hal tersebut bertentangan dengan kaidah tasharuff al imam 'ala al raiyyah manuthun bi al mashlahah.Karena diupayakan Segala 
kebijakanpemerintahsemestinyaberorientasi kepada kemaslahatan ummat. Sudah semestinya berbagai kasus yang menimpa para TKW jangan selalu disederhanakan dengan alasan apapun, termasuk alasan perbedaan kultur sekalipun.

Perubahan paradigma tentang TKW sangat diperlukan untuk menempatkan TKW pada status yang lebih koprehensif dalam dimensi kemanusiaan. Yaitu merubah paradigma developmentalis menjadi paradigmayang lebih humanis.

Untuk melindungi hak-hak dan kewajiban TKW, dibutuhkan kerja sama yang mengikat disegala lapisan dan dikuatkan dengan kepastian perangkat hukum yang secara khusus melindungi kepentingan TKW. Hal tersebut harus dibangun dan dibentuk dengan menyertakan TKW, LSM, Ormas, Parpol, Kemenakertrans, kementrian terkait, perguruan tinggi, Pemuka Agama, media masa dan Praktisi Hukum, yang dikuatkan dengan dasar hukum yang pasti. Perangkat hukum untuk perlindungan TKW harus menjadi prioritas utama dan dikuasai sepenuhnya pemahaman serta implementasinya oleh TKW yang akan bekerja ke Negara tujuananya. Dari sinilah betapa pentingnya peran semua pihak dan TKW beserta komunitasnya membangun komunikasi yang bersifat partisipasif, memberdayakan dan berkelanjutan. Secara teknis dapat diwujudkan dengan cara membangun atau menumbuhkan pusat - pusat pelayanan dan informasi di tingkat Desa yang dikoordinasikan dengan tingkat kecamatan dan seterusnya.

\section{DAFTAR PUSTAKA}

Anthony Giddens. The Third Way: jalan ketiga pembaharuan demokrasi social, Jakarta: Gramedia, 1999

BaniSadr.Buruh, kerja EIslam. Yogyakarta: Shalahuddin Press, 1985.

Franz Von Magnis, Soerjanto pospowardojo \& Bertens (red). Sekitar Manusia (bunga rampai tentang filsafat manusia. Jakarta:

\section{Saran}

Dibutuhkan program yang jelas dan harus memiliki dimensi: pertama, Community base, menempatkan TKW dan keluarganya sebagai subjek sehingga segala persoalan yang berhubungan dengan TKW diurus, dilayani, diputuskan dan hasilnya diperuntukan demi kepentingan TKW dan keluarganya; kedua, kepastian Hukum, TKW dan keluarganya harus mendapatkan perlindungan hokum untuk kepentingan hak - haknya; ketiga ekonomi,TKW dan keluarganya mampu mengelola hasil yang diperoleh selama menjadi TKW untuk kesejahteraanya beserta keluarganya; keempat Sosial Budaya, TKW mampu menjaga martabat, kehormatan, berdaya dan mandiri sebagai bangsa yang memiliki indetitas yang jelas; kelima Humanisme, antara TKW yang berkerja terpisah dengan keluarganya mampu menjaga sikap saling menghormati, menghargai dan dapat berkomunikasi secara baik dan produktif.

Dalam rangka memaksimalkan perlindungan hukum terhadap TKW di luar negeri, sudah saatnya diperkuat lagi regulasi dengan menggagas konsep liabilitas hukum. Liabilitas harus dipandang sebagai tanggung jawab, keadaan dari seseorang yang terikat denganhukum dankeadilanguna melakukan sesuatu yang mungkin dipaksakan melalui tindakan. Artinya, kondisi suatu persoalan yang muncul harus memberikan reaksi untuk suatu kewajiban dalam melakukan hal khusus yang dapat dipaksakan melalui tindakan pengadilan.

gramedia1983

Madelina K. Hendytio Onny S. Prijono \& AMW Pranarka (penyunting). Pemberdayaan, konsep, kebijakan $\mathcal{E}$ Implementasi. Jakarta: CSIS, 1996

Padriono, sugiyanto, heru santoso dan hesti R. wijaya. Liku-liku perjalanan TKI/TKIW berdokumen ke Malaysia. Malang: Gema Press, 1999 